\title{
The Allowable Burn Effect: Does Carbon-fixing offer a New Escape from the Bogey of Compound Interest? ${ }^{1}$
}

\author{
by Colin Price ${ }^{2}$
}

\begin{abstract}
Forestry's long production period entails compound interest, often making investments unprofitable. Several plausible but dubious arguments purport to excuse forestry from bearing compound interest: the existence of externalities, the invalidity of social discounting, the ability of previous revenues to bear replanting costs. The so-called "allowable cut effect" permits comparison of improvement expenditures with immediate yield. In a somewhat similar way, planting forests to absorb carbon dioxide permits almost-immediate burning of fossil fuel, a benefit offering simple interest on the planting costs. Such carbon-fixing plantations appear to be economic even when it is uneconomic to plant for fuelwood production. In one case study, the unit cost of growing wood for burning was $£ 356$ per tonne coal equivalent, while the cost of carbon fixing was only $£ 76$ per tonne of coal burned. The economic acceptability of such planting is not, however, established: particularly, fossil fuel burning may have other malign effects.
\end{abstract}

\section{Introduction}

At least since the days of Martin Faustmann, foresters have lived under the shadow of compound interest (Gane and Linnard 1968). Repeatedly, studies have shown that, under conventional criteria of profitability appraisal, the long delay between costs of planting and revenues from felling makes investment in plantation forestry unprofitable in much of the Northern Temperate Zone (e.g. Hampson 1972, Hyde 1981). Even incorporating the more profitable wood processing element of the forestry industry does not always assure a commercially acceptable rate of return (Sedjo 1984). Under tropical conditions, high rates of growth are often offset by high interest rates resulting from risk premiums (Trivedi and Price 1988). Even in the Southern Temperate Zone, it is only possible to keep ahead of interest rates by using high-quality sites and drastically shortening rotations (Fenton and Sutton 1968).

This article discusses why the compound interest problem is endemic in conventional forestry, and reviews the (usually false) arguments that foresters have raised to excuse plantations from bearing interest. It introduces "the allowable burn effect', under which burning coal to generate electricity is allowed only if forests are planted to fix an equivalent amount of carbon. An economic comparison is made between fuelwood plantations and carbon-fixing plantations, using a British example. On this basis, it is suggested that the allowable burn effect does represent a legitimate way to commute

\footnotetext{
${ }^{1}$ An early version of this paper was submitted in January ' 90 .

${ }^{2}$ School of Agricultural and Forest Sciences, University College of North Wales, Bangor, Gwynedd, U.K.
}

\section{Résumé}

Les longues rotations en foresterie comportent un intérêt composé, qui souvent rend l'investissement non rentable. Plusieurs arguments plausibles mais équivoques tendent à excuser la foresterie de comporter de l'intérêt composé: l'existence d'éléments extérieurs, l'invalidité de ne pas tenir compte de l'aspect social, la capacité des revenus antérieurs de comporter des coûts replantage. L'effet ainsi nommé de "coupe permissible" laisse la possibilité de comparer les coûts des dépense d'amélioration et dans une semblable mesure, la plantation d'arbres pour absorber le bioxyde de carbone permet quasi immédiatement de brûler des combustibles fossiles un bénéfice comportant un intérêt simple sur les coûts de reboisement. De telles plantations fixatrices de carbone semblent économiques même lorsqu'il n'est pas rentable de reboiser à des fins de production de bois de chauffage. Selon une étude de cas, le coût unitaire de production de bois de chauffage totalisait $356 £$ la tonne equivalente de charbon, alors que le coût de fixation était de seulement de $76 £$ la tonne de charbon brûlé. L'acceptabilité économique d'un tel reboisement n'est pas établi, mais souligne en particulier que la combustion de combustible fossiles peut comporter d'autres effets pernicieux.

the effect of compound interest, though questions are raised about the permanence of carbon-fixing and about the costs imposed by other combustion products. Parallels between the allowable burn effect and the familiar allowable cut effect are noted as they arise.

\section{Compound Interest and Forestry}

The problem for investment in forestry, as opposed to agriculture, arises because the biological product cannot be sold in the year during which it is produced. Thus, even if interest is added only annually, the time lapse entails compound rather than simple interest on investment. The lapse is unavoidable for four fundamental and interlocking reasons.

(a) Conventional forest crops have slow initial growth rates, compared with annual crops. This reflects a difference of competitive strategy between woody perennials and herbs. In the Northern Temperate Zone the period of plantation establishment, before rapid biomass increment begins, may last for several years.

(b) The generally low value-for-bulk of the product, compared with food crops, means a longer period of biomass accumulation is needed before the initial planting costs are recovered. For example, even if sawlog prices were immediately obtained by an average British forest, four years' increment would be needed just to repay establishment cost.

(c) But sawlog prices cannot be obtained immediately. Unlike crops for which only mass per hectare imparts value to the product, timber crops are usually unsalable until individual tree stems have attained substantial size (after 12-25 years for conifers in Britain). This fact 
reflects partly the less valuable end-uses of small trees, and partly the high cost (using current individual-tree harvesting technologies) of felling, converting and transporting them. Beyond this time, many further years elapse before any stems in the crop can obtain sawlog prices.

(d) Unlike fruit trees, in which product (fruit) and capital (tree) are separable entities, timber trees are both product and capital. If the product is sold early, production terminates and the cost of establishment is incurred again.

To some extent these problems are overcome by shortrotation biomass forestry using coppicing species. For conventional forestry, however, compound interest over long periods remains a central and apparently intractable problem.

\section{Traditional Escape Routes}

Foresters have, over the years, tried to evade the "bogey of compound interest" (Shepard 1925) in a number of ways. One way has been to argue the existence of positive externalities (amenity, recreation, conservation) which improve the performance of the investment (Society of Foresters of Great Britain 1973, Leslie 1987). (Negative externalities are also clearly demonstrable (e.g. Barrow et al. 1986), but are less often mentioned.) Unfortunately, many of the benefits only emerge as the crop matures, so compound interest is unfavourable to them too. They constitute an argument for prolonging rotations already running (Calish et al. 1978, Price 1988b) more than for establishing crops in the first place.

Another defence has been to argue a case for a low sometimes a specially low - rate of interest to appraise forestry (Price 1973, 1988a; Helliwell 1974, Harou 1985). Some of the contentions use inverted logic, arguing from the desirability of profit to the necessity of low interest rates (Royal Scottish Forestry Society 1972). Others have focused on the special qualities of forestry (Leslie 1967) or the inapplicability of market rates of return to social discounting (Feldstein 1964, Price 1990). But whatever the theoretical validity of these arguments, the painful practical fact is that private banks and public treasuries set rates of interest that are often beyond forestry's power to achieve.

There remains, however, a strong tradition among foresters which asserts that, where forests already exist, the cost of replanting should be a charge against the rotation just ended, rather than the one that is to come (Garfitt 1986). If cost is immediately paid off using felling revenue, there is nothing left to charge interest on, and the interest rate becomes a matter of indifference.

This viewpoint may spring from a semi-mystical philosophy that "forests are a gift of nature" (Markus 1967), which "ought" to be replaced - perhaps in order to leave future generations the legacy that we ourselves received. Others argue more pragmatically, that a forest service or estate enterprise in regular annual surplus from profitable fellings does not have to cozen fresh funds from treasuries or banks. The fact that the optimal rotation without compound interest produces a greater annual surplus than the conventional financial optimum (Tait 1987) reinforces the perceived case for ignoring compound interest. The apparent plausibility of these arguments explains why regions like continental Europe and North America, with a large remnant of natural forest capital, have shown less concern about compound interest than Britain, which depends heavily on artificial plantations.
Neither the mystical nor the pragmatic view takes account of opportunity cost: in alternative investments, the funds devoted to replanting might have yielded greater returns to future generations, governments or bank balances. The prevailing rate of interest measures (it is usually agreed) that opportunity cost. Nor are these viewpoints causally sound, since "Whatever else results from replanting, it cannot be revenue from a crop already felled and sold" (Price 1989, p. 106).

Despite these reservations, there are clearly cases where the cost of replanting has to be considered along with the revenue from felling; when forests perform a primarily protective role, for example, or when permission to fell is made conditional upon an undertaking to replant. In these cases, however, it is the legal or physical constraint, not economic considerations, that forces replanting cost onto the previous rotation. The economic decision is not about replanting, but, given the constraint (which may or may not be economically sensible), about whether it is worth felling and replanting, now, later, or ever.

\section{The "Allowable Cut Effect"}

A more recent attempt to circumvent compound interest relies on the effect of sustained yield constraints. Under such constraints, the allowable cut in a given time period depends on the volume that will be available in future time periods. Therefore any action now which increases that availability such as fertilizing an immature crop - allows an increased annual cut from now onward (Schweitzer et al., 1972, Binkley 1984), provided that mature forest stands are available for immediate felling. It seems that investment has initiated an immediate rather than a long-delayed increase in revenue flow: it can be judged on the basis of simple rather than compound interest.

For example, fertilizing an immature plantation at a cost of $£ 3000$ might increase its expected volume after 25 years by $500 \mathrm{~m}^{3}$, with a value of $£ 35 / \mathrm{m}^{3}$. Judged as a selfcontained investment, this earns compound interest at $7.3 \%$. However, suppose an old-growth stand exists in the same forest, with volume $500 \mathrm{~m}^{3}$ and zero net increment. It was originally scheduled for felling after 25 years. However, its place in the cutting programme can now be taken by the expected increased volume of the fertilized stand. Cutting of the old-growth stand can be started immediately at a sustained rate of $20 \mathrm{~m}^{3}$ per year, worth $£ 700$. This yields continuous simple interest at $23.3 \%$ (equivalent to an annual percentage rate of $26.3 \%$ ).

The validity of the so-called allowable cut effect has been challenged (Teeguarden 1973). Particularly, it depends on the immovability of the sustained yield (or other harvesting schedule) constraint. Given the constraint, fertilizing investment does evidently result in a high rate of return. Economists might, however, wish to add the option of not fertilizing, but taking an increased old-growth cut anyway. The question then is: does the increase in future harvest resulting from faster growth produce an acceptable compound rate of return on investment in fertilizing now?

\section{Sustainable Development and "Allowable Burn"}

There are strong parallels between foresters' concerns with sustained yield and the fashionable economics of sustainable 
development. In particular, the sustained yield constraint embedded in the allowable cut effect is an example of the "non-declining natural wealth"' concept (Pearce et al. 1989, pp. 37-40). Depleting the natural capital of an old-growth stand is admissible only if an "environmentally compensating project" (Pearce et al. 1989, pp. 127-8) is instituted to replace it - in this case by accelerating the growth of another stand.

Another recent preoccupation of environmentalists and sustainable development theorists alike has been the greenhouse effect, or global warming, in which foresters also have an important potential role. Public concern and private conscience about global warming have been roused to the point that there is even talk of doing something about it. In particular, power generation companies, who are major producers of greenhouse gases, have become involved in planting forests to absorb carbon dioxide, and thus, redress the atmospheric balance disturbed by burning fossil fuels.

This response too is an example of an environmentally compensating project. In this case the natural wealth to be maintained is not the forest itself, but the natural asset represented by the Earth's present atmospheric composition. Just as the fertilizing project replaces the depleted natural wealth of the old-growth stand by increment of the immature one, so the carbon dioxide absorbing plantation is intended to restore the atmospheric asset degraded by power generation. Both these environmentally compensating projects meet the "strong sustainability" criterion (Pearce et al. 1989, p. 127). That is to say, they ensure that the environmentally adverse effects are balanced by positive effects in each time period. The sustainability criterion also requires that the cost of the environmentally compensating project should be included in the economic assessment of electricity generation. Such a costing is attempted later in this paper.

Because of conceptual parallels with the allowable cut effect, the balancing of fossil fuel burning by compensatory plantations is herein referred to as "the allowable burn effect'. Further parallels, with particular emphasis on interest-earning, emerge later. First, however, the essential biophysical factors in carbon absorption are reviewed.

Carbon cycling and storage in forest ecosystems are complex processes (Schlesinger 1977, Cooper 1983, Detwiler and Hall 1988). Most carbon accretion in biomass is the result of net assimilation (photosynthesis minus respiration), but some carbon transactions take place with the soil: soil carbon accretion occurs in growing forests (Johnson and Sharpe 1983), while forest harvesting or cultivation for afforestation may initiate carbon oxidation in organic soils (Cropper and Ewel 1984). Assimilated carbon does not remain fixed permanently, but, depending on the end use of wood, may be restored as atmospheric carbon dioxide quite rapidly (Thompson and Matthews 1989, Dewar 1990). Alternative scenarios for restoration and re-assimilation are discussed later.

Not all effects of global warming are expected to be adverse. Some hypothesized climatic changes would be advantageous to plant growth. (Sedjo (1989) suggests that the annual atmospheric increase of carbon could be balanced by " a warming-induced northward expansion of 3.5 billion hectares of forests".) It is not known whether carbon dioxide availability is a significant global limitation on photosynthesis
(Kauppi 1987), but if it were, then increased concentrations would have some beneficial effect (Cooper, 1983). There is even debate about whether global warming is serious at all (Michaels 1989).

Nevertheless, despite the complexity of mechanisms and uncertainty of outcomes, the pragmatic presumption seems to favour making cautious assumptions and maintaining what stability we have in the planet's atmospheric composition. It is in this political context that locking up carbon dioxide is seen as a desirable or even necessary concomitant of continued fossil fuel burning.

\section{The Unit Cost of Fossil Fuel Replacement}

The process of growing trees to fix carbon in order to allow fossil fuels to be burned may strike foresters as unnecessarily convoluted. Why not tackle the problem head-on, by establishing fuelwood plantations to feed power stations directly? This would achieve the same zero net effect on atmospheric carbon, while reducing dependence on nonrenewable natural resources. Moreover, if it is economic to plant a forest to absorb the carbon dioxide released by burning fossil fuels, is it not economic to plant a forest to replace the use of fossil fuels?

The possibilities of wood-burning power stations are indeed discussed by Earl (1975) and Frankena (1987), but they are rarely considered seriously for production of electricity on a national scale. The problem for a densely-populated country is clear from the fact that it would take more than the sustained yield from the entire forest area of Britain to supply a single 2500 megawatt power station, which itself would contribute only a few percent of the nation's electricity consumption. Frankena (1987) suggests a 5 megawatt unit as a desirable size for wood-fired power stations in the United States.

Partly, the uneconomic nature of plantation-fed power stations results from the less concentrated availability of wood compared with fossil fuels, given modern generating units with large economies of scale. And partly it follows from the cost of growing fuelwood, when compound interest at commercial rates is charged on the cost of plantation establishment.

To demonstrate this point, an illustrative calculation is given in Table 1. The objective is to show the cost, including interest, of growing fuelwood with an energy-value equivalent to one tonne of coal of the grade normally used in electricity generation in Britain. The crop is Sitka spruce of yield class 12 . Plantations of this species and productivity are commonly found in the uplands of Britain, where most afforestation has occurred this century.

Physical yield for the plantation is as given by Forestry Commission (1981). Energy values are derived from data in Earl (1975). For simplicity the crop is grown on a nothin regime, and a rather skeletal cash flow, using reasonable figures for Britain, is assumed. The interest rate is $7 \%$. This is the average of required rates of return on government investment in Britain over the last few years, and also represents the approximate difference between the bank base lending rate and the inflation rate in Britain. Under these circumstances the financially optimal rotation for fuelwood production is about 35 years.

The resulting cost, $£ 356$ per tonne coal equivalent, compares very unfavourably with the current delivered price of 
Table 1. Cost per tonne coal equivalent of delivered wood fuel

\begin{tabular}{lrrc}
\hline EXPENDITURE & Year & $\begin{array}{l}\text { Cost } \\
(\mathfrak{(} / \mathbf{h a})\end{array}$ & $\begin{array}{l}\text { Cost plus interest } \\
\text { to year 35 }(\boldsymbol{(} / \mathbf{h a})\end{array}$ \\
Operation & 0 & 400 & 4271 \\
\hline Land purchase & 0 & 1000 & 10677 \\
Establishment $^{\text {Annual management }}{ }^{1}$ & $0-35$ & 25 & 3576 \\
Land resale $^{\text {Summed compounded cost }}$ & 35 & -400 & -400 \\
\hline
\end{tabular}

\section{OUTPUT}

Total yield at year $35\left(\mathrm{~m}^{3} / \mathrm{ha}\right)^{2}$ 255

UNIT COSTS $\left(£ / \mathrm{m}^{3}\right)$

Growing (expenditure/output) $18124 \div 255=71$

Felling and trimming

Extraction to roadside

Transport to power station

Total

8

7

89

CONVERSION OF OUTPUT COST TO COAL EQUIVALENT COST

Energy value conversion from $\mathrm{m}^{3}$ to tonnes coal equivalent $4: 1$

Total cost per tonne coal equivalent ( $£$ /tce)

$89 \times 4=356$

'Since management costs are incurred continuously over time, the formula used is the one for the terminal value of a continuous terminating series: $£ 25 \times\left(1.07^{35}-1\right) \div$ In $(1.07)$. Use of $\ln (1+r)$ in place of $r$ as a discount rate for continuous flows, although unfamiliar to foresters, is normal in natural resource economics, and gives a more accurate result.

${ }^{2}$ Technically, the maximum mean annual increment per hectare from yield class 12 is $12 \mathrm{~m}^{3}$, giving $420 \mathrm{~m}^{3}$ at year 35 . This figure is not achieved because of the suboptimal thinning regime and rotation for maximum (undiscounted) biomass increment, and is further reduced by $15 \%$ to allow for unproductive areas (roads, rides and understocked land). This gives an effective mean annual increment of $8.5 \mathrm{~m}^{3} /$ ha/year over the period 5-35 years.

coal to major industries, about $£ 75$ per tonne. Even the harvesting and transportation costs make wood barely competitive. Adding compound interest on growing costs shows that such plantations are very far from being an economic substitute for fossil fuels at current market prices. (A different result might emerge if the future opportunity costs of fossil fuel depletion were inserted (Price 1984).)

\section{The Unit Cost of Carbon-fixing Plantations}

The economics of fuelwood plantations may now be contrasted with those of carbon-fixing plantations. Let it be accepted that atmospheric constraints allow the burning of fossil fuels only if a quantity of carbon equivalent to that released in combustion is locked up by growing trees. In that case, the value of fossil fuel can begin to be realized shortly after the costs of establishing the plantation are incurred, as soon as net carbon fixing begins. This in effect allows the increment of the tree to be taken as it grows, rather than at the rotation end. The tree as productive capital can be maintained, while the benefits of the tree as biomass product are realized. At the same time the atmospheric capital from which flow the sustained annual benefits of a stable climate is kept intact.

Furthermore, because the value of trees now lies in their existence as a store of fixed carbon, rather than in their removal from site for processing, the high unit costs of harvesting small trees are no longer incurred. The relative dispersion of the resource compared with coal is not a problem, nor is its heavy transport cost to centres of electricity generation. It seems that the three birds of low form utility, low place utility and low time utility have been killed with a single environmental stone! Let us examine the economic calculation under an allowable burn constraint.
Firstly, lacking better data, a direct equivalence between carbon burned and carbon that the trees are required to take up is assumed: there is no removal of carbon from flue gases in power stations, and carbon transactions of trees are all with the atmosphere.

Secondly, the fossil fuel value cannot be claimed instantly, since in temperate conditions it might take five or more years for the planted crop to start acquiring significant biomass; in the tropics, perhaps it would be only one or two. For simplicity it has been assumed that total biomass increment is constant from year 5 to year 35 . In practice, of course, biomass increment increases steadily from time of planting for a period of many years.

Harvesting and transportation are unnecessary. The only relevant costs are those of land purchase, establishment and management, plus the interest charges on them. The benefits of burning coal equivalents are now spread over a long period, unlike the fuelwood plantation, which produces its output at one point in time. This necessitates a different approach to charging interest. A breakeven unit price per tonne coal equivalent is defined for carbon-fixing services, at which a forest investment would cover its costs by the end of the rotation. As this price is levied on a power generating company, it becomes a positive item in the forest accounts, attracting interest over the remaining period of the rotation. Thus, the compounded value at rotation age $T$, of an allowable burn $X_{t}$ tonnes at time $t$, with a decimal interest rate of $r$ is given as

[unit price] $\times X_{\mathrm{t}} \times(1+r)^{(\mathrm{T}-\mathrm{t})}$

and the summed compounded value at $T$ is

$\sum_{t=C}^{r=T}$ [unit price $] \times X_{\mathrm{t}} \times(1+r)^{(\mathrm{T}-\mathrm{t})}$

where $C$ is the time when carbon fixing commences.

$=[$ unit price $] \times\left\{\sum_{t=C}^{t=T} X_{\mathrm{t}} \times(1+r)^{(\mathrm{T}-\mathrm{t})}\right\}$

For continuous carbon fixing at annual rate $X$, from $C$ to $T$, the appropriate formula is that for the terminal value of a $(T-C)$-year continuous cash flow:

[unit price] $\times\left\{X \times\left((1+r)^{(\mathrm{T}-\mathrm{C})}-1\right) \div \ln (1+r)\right\}$

The terms in curly brackets may be called for convenience the "summed compounded tonnes" of allowable burn. This is used as a computational convenience, and should not be given any conceptual meaning.

For the investment to break even, [unit price] times [summed compounded tonnes] must equal [compounded net cost] for the rotation. Thus by rearrangement:

$$
\text { [unit price }]=\frac{[\text { compounded net cost }]}{[\text { summed compounded tonnes }]}
$$

Table 2 shows the necessary calculations, with conversion factors again derived from Earl (1975). The result is a carbon-fixing cost per tonne of coal burned of $£ 76$.

The method is similar to the "discounted output solution" proposed for costing machinery (Price 1985, 1989, pp. 71-5). Indeed, dividing [discounted net cost] by [summed discounted tonnes] is an alternative approach to the above calculation, which yields an identical result.

Although the rotation has been kept at 35 years to aid 
Table 2. Cost per tonne coal equivalent of carbon dioxide fixing

\section{EXPENDITURE}

Summed compounded cost of rotation (from Table 1)

18124

OUTPUT

Annual stem increment from year 5 to year $35\left(\mathrm{~m}^{3} / \mathrm{ha} / \mathrm{yr}\right)^{1}$

CONVERSION OF OUTPUT TO COAL EQUIVALENT

Conversion to whole biomass increment ${ }^{2}$ 列 $\div 0.65$

Whole biomass increment $\left(\mathrm{m}^{3} / \mathrm{ha} / \mathrm{yr}\right)=13.1$

Conversion factor $\mathrm{m}^{3}$ to oven-dry tonnes $\quad \times \quad 0.32$

Whole biomass increment (tonnes/ha/yr) $=4.18$

Carbon as proportion oven-dry weight $\quad \times \quad 0.5$

Carbon fixed (tonnes/ha/yr) $=2.09$

Carbon per tonne of coal $\div 0.86$

Tonnes of coal equivalent to annual carbon fixed $=2.43$

\section{UNIT COST}

Summed compounded tonnes coal from year 5 to year 35 (tce/ha) ${ }^{3}$

$\left\{2.43 \times\left(1.07^{(35-5)}-1\right) \div \ln (1.07)\right\}=237.5$

Cost per tonne coal $(\mathfrak{f} /$ tonne $) \quad 18124 \div 237.5=76$

'The mean value is assumed to accrue each year.

${ }^{2}$ Approximately $65 \%$ of yield is in the stem for this species and regime. ${ }^{3}$ See formula (3) in text.

comparison with Table 1, in the new circumstances a longer rotation gives both a higher mean annual increment and a more prolonged period of carbon fixing. Parallel calculations based on the mean increment of a crop felled at 56 years (the time of maximum mean annual increment) would have given a cost of $£ 60$ per tonne.

Both unit prices are far below the unit cost calculated for the fuelwood plantation.

It should be stressed that the particular figures are not universal ones - indeed parallel calculations for other species, costs and circumstances would provide an interesting further study. For example tropical plantations would be more productive, but face higher interest rates; slower-growing species might have greater air-dry density. Nonetheless, the clear difference between the economics of a fuelwood plantation and those of a physically identical carbon-fixing plantation would persist for any reasonable figures.

\section{At the End of the Rotation, What Next?}

What happens after age 35 profoundly affects interpretation of the allowable burn effect. The implicit assumption in Table 2 is that at the end of the rotation the land will be sold and the trees will be costlessly harvested and stored. There will be no release of carbon dioxide by degradation of any biomass, including stump, roots and branches. Clearly this is unrealistic. Four alternative prospects may be contemplated (see also Thompson and Matthews (1989)).

1. As degradation takes place, it is balanced by forgoing other carbon dioxide generating activities, e.g. by reducing fossil fuel burnt. Eventually all the original allowable burn will be clawed back. But in discounting terms this postponed cost is much less serious: the whole cycle can be interpreted as a means of buying time until replacement technologies are developed for energy-generation or for fixing atmospheric carbon permanently.

2 . The wood from the plantations is gradually sold as fuel, and the land remains in timber production. Burning of the wood should not exceed the net rate of biomass accretion in the replacement crop. The revenue from sales need cover only the costs of harvesting, transporting and replanting the successor crop, so again compound interest on growing the crop has been avoided. (Similar costs to those incurred in growing the successor crop would also be incurred to allow burning of coal.) The cost of harvesting and transportation per tonne coal equivalent, £72, is now competitive with burning coal.

3. At present prices sale of wood as a structural material is likely to be more lucrative. It also offers the following energy advantages:

(a) while the wood remains undegraded, increment of the replacement crop allows further burning of coal;

(b) structural use to replace steel members could save 10-20 times the direct coal equivalent value of the wood (Barrow et al. 1986).

4. In practice there will be mixed use. Some burning and decay can be balanced by increment of the next crop. Any net accretion of fixed carbon increases the allowable burn of fossil fuel. It should be noted, however, that sustained yield of wood from a site does not imply sustained allowable burn, because a percentage of wood degradation is inevitable. Structural timber and forest residues decay slowly or rapidly respectively; a high proportion of offcuts and paper products either are burned or decay quickly.

\section{The Effect of Circumventing Compound Interest}

On reasonable assumptions, the cost of carbon fixing is spectacularly less than the cost of supplying wood fuel. To complete the comparison, however, the three options that yield one tonne coal equivalent should be compared:

1. to burn wood currently standing in forests that is not needed for other purposes (harvesting and transportation cost $=£ 72$;

2. to grow wood for burning (growing, harvesting and transportation cost $=£ 356$ );

3 . to burn coal (mining and transportation cost $=£ 75$ ).

Options 1 and 3 both entail an additional cost of £60-76 for carbon reabsorption. Even so, they are far cheaper than option 2, because the effect of compound interest is largely circumvented. (There is a short period of compound interest accrual up to year 5, when the first allowable burn occurs.)

The analysis can be pressed a little further. Suppose that an alternative means of electricity generation, without significant pollution, is proposed to replace some thermal generating capacity. Suppose that the cost of this alternative is such that thermal generation remains cheaper up to a fuel cost of $£ 200$ per tonne of coal. Since the delivered cost of the coal itself is $£ 75$, then up to $£ 125$ can be afforded for each tonne coal equivalent of carbon fixed in the forest. Using this as a unit price for carbon fixing, the annual value of the forest from year $5-35$ is 2.43 tonnes coal equivalent $\times £ 125 /$ tonne $=£ 304$. The internal rate of return of the carbon fixing plantation is $11.2 \%$.

By contrast, the stumpage value of fuelwood is $£ 32 / \mathrm{m}^{3}$ ( $£ 200 /$ tonne of coal $\div$ [conversion factor for $\mathrm{m}^{3}$ to tonnes] - [harvesting and transportation $\left.\cos t / \mathrm{m}^{3}\right]$ ), giving an annual value of increment from year $5-35$ of $£ 32 / \mathrm{m}^{3} \times$ $8.5 \mathrm{~m}^{3}=£ 272$. This yields an internal rate of return for the fuelwood plantation of $4.5 \%$. The difference of annual revenue (due to the difference between the calorific value of the harvested wood and the calorific value of the elemental 
carbon content of the whole tree) is slight. The major improvement in IRR under the allowable burn effect derives from similar causes to (though is less dramatic than) the high IRRs generated by the allowable cut effect (Schweitzer et al. 1972). In both cases the realization of benefit as increment accrues (rather than when the crop is felled) is the fundamental characteristic. In both cases this empowers the forest to yield simple interest.

But, as in all the earlier arguments against application of compound interest, the allowable burn effect assumes the existence of an inviolable constraint. The allowable burn constraint at present owes more to a sense of cautiousness about global warming than any certain calculation of its malign effects. Economists have the tools to evaluate the cost of incremental release of carbon dioxide, in terms of sea-defence works built, productive land lost, impact of drought on agriculture and so on. What are lacking are accurate and agreed predictions of the physical effects. When these are better known, it will be possible to compare, tenuously perhaps, the cost of establishing carbon-fixing forests with the benefits of reducing the greenhouse effect. Since many of those benefits will extend far into the future, the influence of the interest rate in appraising the investment will again be exerted.

The consequences of fossil-fuel burning are not, of course, confined to those presented here. Sulphur and nitrogen oxides released from power stations are greenhouse gases that are not incorporated in growing plantations in proportion to carbon dioxide. While their greenhouse role may be minor, moreover, they are deeply implicated in acidic precipitation. When such precipitation kills trees that might otherwise have been photosynthesizing, and furthermore results in them decaying instead, the complexity of interactions begins to be revealed, and some circumspection is appropriate in welcoming the newfound greenhouse-consciousness of the power companies. Another environmentally compensating project to remove acidic combustion products or repair the damage they cause is needed before the environmental account is complete, and its cost must be added to the cost in Table 2 .

\section{Conclusion}

If burning fossil fuels is allowable only on payment of restitution in the form of new planting, the allowable burn effect does offer a new escape from the bogey of rotation-long compound interest. This is so, whatever the intended end-use of the forest created, given only that the forest was planted as a concomitant of burning fossil (or even biomass) fuels. The mechanism works, not by denying the relevance of interest, but by relating forest investment costs to the simple interest represented by biomass increment. The notion of strict sustainability represents a contemporary legitimation for this procedure within (relatively) mainstream economics.

In the second section of this paper, four reasons were given for the pervasiveness of compound interest in forestry. The allowable burn effect partly evades reason (c) - the high cost of harvesting small stems - and wholly evades reason (d) the inseparability of forest product and forest capital. Reason (a) - slow initial forest growth - remains, and accounts for the period of compound interest accumulation up to the point where significant carbon fixing begins. Reason (b) - the long period to recovery of establishment costs - would become less significant if allowable fossil fuel burning came to have a higher value.
For forest economists who have fashioned careers from challenging the social relevance of compound interest over long spans of time, the allowable burn effect may not change the perception of forestry's profitability. It merely increases the range of assumptions under which plantations can be justified. But for politicians and treasury officials, aware as never before of The Environment, it offers a dramatically new prospect of swift return from plantation forestry. This paper has shown that the effect can transform the conventional economics of energy forestry.

But let all things be done in due order and with due wariness. There may be more to be gained, sooner, by other management options. Prolonging the rotations of existing crops gives additional carbon-fixing without the delay of establishment, as does fertilizing them so that they grow faster. Not replacing one hectare of tropical forest by low-biomass annual crops gives immediate retention of fixed carbon, equivalent to what a hectare of Sitka spruce would need about 50 years to assimilate (based on figures in Detwiler and Hall (1988)). And, given that the malign effects of fossil fuel depletion extend beyond global warming, economy in the use of energy is perhaps the really urgent imperative. If it merely accompanies a licence to pollute, the allowable burn effect could be the most pernicious perversion of the case against compound interest that foresters have yet countenanced. If for no other reason, the merit of carbon-fixing plantations is not yet proved.

\section{Acknowledgement}

I am grateful for the detailed comments of an anonymous reviewer on an earlier version of this paper.

\section{References}

Barrow, P., A.P. Hinsley and C. Price. 1986. The effect of afforestation on hydroelectricity generation: a quantitative assessment. Land use Policy 3: 141-151.

Binkley, C.S. 1984. Allowable cut effects without even flow constraints. Can. J. For. Res. 14: 317-320.

Calish, S., R.D. Fight and D.E. Teeguarden. 1978. How do nontimber values affect Douglas fir rotations? J. For. 76: 217-221.

Cooper, C.F. 1983. Carbon storage in managed forests. Can. J. For. Res. 13: 155-166.

Cropper, W.P., Jr. and K.C. Ewel. 1984. Carbon storage patterns in Douglas-fir ecosystems. Can. J. For. Res, 14: 855-859.

Detwiler, R.P. and C.A.S. Hall. 1988. Tropical forests and the global carbon cycle. Science 239: 42-47.

Dewar, R.C. 1990. A model of carbon storage in forests and timber. Tree Physiology (In press).

Earl, D.E. 1975. Forest Energy and Economic Development. The University Press. Oxford.

Feldstein, M.S. 1964. The STP discount rate in cost-benefit analysis. Econ. J. $74: 360-379$.

Fenton, R.T. and W.R.J. Sutton. 1968. Silvicultural proposals for radiata pine on high quality sites. N.Z. J. For. 13: 220-228.

Forestry Commission 1981. Yield models for forest management. For. Comm. Booklet 48.

Frankena, F. 1987. Rethinking the scale of biomass energy conversion facilities: the case of wood-electric power. Biomass 14: 149-171.

Gane, M. and W. Linnard. 1968. Martin Faustmann and the evolution of discounted cash flow. Common. For. Inst. Pap. 42.

Garfitt, J.E. 1986. The economic basis of forestry re-examined. Quart. J. For. 80: 33-35.

Hampson, S.F. 1972. Highland forestry: an evaluation. J. Agric. Econ. 23: 49-57.

Harou, P.A. 1985. On a social discount rate for forestry. Can. J. For. Res. 15: $927-934$. 
Helliwell, D.R. 1974. Discount rates in land use planning. Forestry 47: 147-152.

Hyde, W.F. 1981. Timber economics in the Rockies, efficiency and management options. Land Econ. 57: 630-638.

Johnson, W.C. and D.M. Sharpe. 1983. The ratio of total to merchantable biomass and its application to the global carbon budget. Can. J. For. Res. 13: 372-383.

Kauppi, P. 1987. Forests and the changing chemical composition of the atmosphere in M. Kallio, D.P. Dykstra and C.S. Binkley (eds.) The Global Forestry Sector. Wiley, New York.

Leslie, A.J. 1967. Cost-benefit analysis in relation to plantation development projects. Austral. For. 31: 19-32.

Leslie, A.J. 1987. A second look at the economics of natural management systems in tropical mixed forests. Unasylva 39: 46-58.

Markus, R. 1967. Ostwald's Relative Forest Fent Theory. Bayerischen Landwirtschaftsverlag. München.

Michaels, P.J. 1989. The greenhouse effect: Chicken Little and our response to global warming. J. For. 87 (7): 35-39.

Pearce, D.W., A. Markandya and E.B. Barbier. 1989. Blueprint for a Green Economy. Earthscan. London.

Price, C. 1973. To the future: with indifference or concern? J. Agric. Econ. 24: 393-398.

Price, C. 1984. Project appraisal and planning for overdeveloped countries. Environ. Manage. 8: 221-242.

Price, C. 1985. Capital costing for forest machinery: a discounted output solution. Scot. For. 39: 77-85.

Price, C. 1988a. Investment, reinvestment and the social discount rate for forestry. For. Ecol. Manage. 24: 293-310.
Price, C. 1988b. Environmental benefits and optimal rotation: consensus? J. Environ. Manage. 27:341-346.

Price, C. 1989. The Theory and Application of Forest Economics. Blackwell. Oxford.

Price, C. 1990. Deforestation and economic criteria. Project Appraisal 5: (In press).

Royal Scottish Forestry Society 1972. Views on Government's forestry policy review of June 1972. Scot. For. 26: 257-261.

Schlesinger, W.H. 1977. Carbon balance in terrestrial detritus. Ann. Rev. Ecol. System. 8: 51-81.

Schweitzer, D.L., R.W. Sassaman, and C.H. Schallau. 1972. Allowable cut effect. J. For. 70: 415-418.

Sedjo, R.A. 1984. An economic assessment of industrial forest plantations. For. Eco. Manage. 9: 245-257.

Sedjo, R.A. 1989. Forests to offset the greenhouse effect. J. For. 87 (7): 12-15.

Shepard, W. 1925. The bogey of compound interest. J. For. 23: 251.

Society of Foresters of Great Britain 1973. A statement of views on forestry policy. Forestry 46: 5-9.

Tait, D.E.N. 1987. The good fairy problem: one more look at the optimum rotation age for a forest stand. For. Chron. 63: 260-263.

Teeguarden, D.E. 1973. The allowable cut effect: a comment. J. For. 71: 224-226.

Thompson, D. and R. Matthews. 1989. $\mathrm{CO}_{2}$ in trees and timber lowers the greenhouse effect. Forestry and British Timber 18 (10): 19-24.

Trivedi, S.N. and C. Price. 1988. The incidence of illicit felling in afforestation project appraisal: some models illustrated for Eucalyptus plantations in India. J. World For. Resour. Manage. 3: 129-140

\title{
University of New Brunswick Faculty of Forestry
}

Applications are invited for a 12-month, tenure-track appointment in Forest Economics at the Assistant Professor rank subject to budgetary approval. A PhD or equivalent experience is required. The appointees will teach undergraduate and graduate courses, supervise graduate students, and will be expected to mount a strong research program.

Preference will be given to those candidates with a strong forestry background who are oriented to social and economic considerations in forest management.

Applications, including a curriculum vitae and names of three referees, should be submitted to:

\author{
Dr. G.L. Baskerville \\ Dean, Faculty of Forestry \\ University of New Brunswick \\ Bag service \#44555 \\ Fredericton, New Brunswick \\ Canada E3B 6C2
}

In accordance with Canadian immigration requirements, this advertisement is directed to Canadian citizens and permanent residents. 